
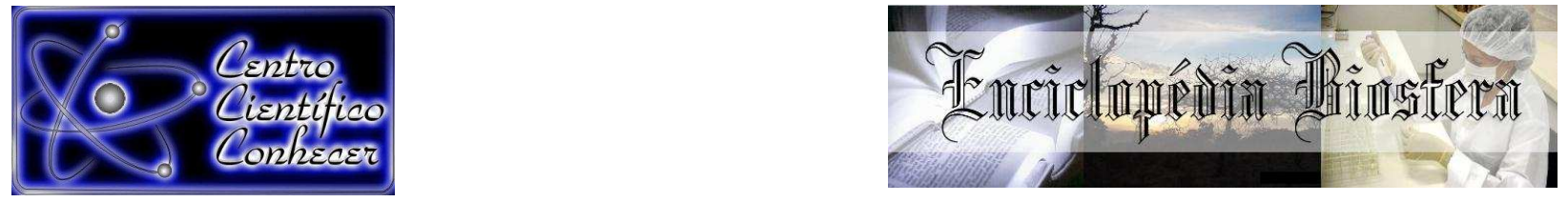

\title{
JEJUM PRÉ-ABATE E SUAS IMPLICAÇÕES NO METABOLISMO ANIMAL, INTEGRIDADE INTESTINAL E QUALIDADE DA CARNE DE FRANGOS DE CORTE
}

\section{Denise Russi Rodrigues ${ }^{1}$, Raisa Brito Santos ${ }^{1}$, Eugênio Gonçalves de Araújo ${ }^{1}$, Marcos Barcellos Café ${ }^{1}$ \\ ${ }^{1}$ Programa de Pós-Graduação em Ciência Animal, Universidade Federal de Goiás, Escola de Medicina Veterinária e Zootecnia EVZ-UFG, Goiânia, GO, Brasil. Email:veterinariadenise@hotmail.com}

Recebido em: 03/10/2016 - Aprovado em: 21/11/2016 - Publicado em: 05/12/2016 DOI: 10.18677/EnciBio_2016B_058

\begin{abstract}
RESUMO
A utilização de jejum pré-abate é uma prática rotineira na indústria avícola e tem por objetivo reduzir a quantidade de digesta no trato durante a evisceração, diminuindo a incidência de ruptura intestinal. Porém, se o período de jejum é exacerbado, ocorre alteração do metabolismo dos frangos de corte, com prejuízos ao bem-estar. 0 estresse causado nesta etapa pré-abate, modifica a microbiota e integridade do epitélio intestinal, aumentando o risco de contaminação da carcaça durante o processamento. Além disso, os parâmetros físicos da carne também podem ser modificados, propiciando o desenvolvimento de defeitos de qualidade da carne. Esta revisão foi realizada para apresentar os principais aspectos do jejum pré-abate de frangos de corte, bem como abordar seus efeitos no metabolismo animal, integridade intestinal e qualidade da carne.
\end{abstract}

PALAVRAS-CHAVE: aves, bem-estar animal, restrição alimentar.

\section{PRE-SLAUGHTER FEED WITHDRAWAL AND ITS IMPLICATIONS ON ANIMAL METABOLISM, INTESTINAL INTEGRITY AND MEAT QUALITY OF BROILER CHICKENS}

\section{ABSTRACT}

The use of pre-slaughter feed withdrawal is a common practice in the poultry industry and aims to reduce the amount of digesta in the tract during evisceration, reducing the incidence of intestinal rupture. However, if the fasting period is exacerbated occurs altered broilers metabolism with losses in welfare. The stress in this preslaughter stage modifies the microflora and integrity of the intestinal epithelium, increasing the risk of carcass contamination during processing. Moreover the physical parameters of the meat can also be modified by providing the developing meat quality defects. This review was conducted to present the main aspects of the broilers pre-slaughter feed withdrawal, as well as address its effects on animal metabolism, intestinal integrity and meat quality.

KEYWORDS: fasting, poultry, welfare. 


\section{INTRODUÇÃO}

O último dia do ciclo produtivo dos frangos de corte é descrito como fase pré-abate. O manejo realizado nesta etapa, inclui o jejum, apanha, carregamento, transporte, espera no abatedouro, pendura e finalmente, a insensibilização. A retirada da alimentação antes do abate é uma prática de gestão comum em produção de frangos de corte comercial, pois permite o esvaziamento do sistema digestivo da ave e reduz os custos com ração (BARREIRO et al., 2012).

Um dos objetivos do jejum pré-abate é minimizar a perda na qualidade do produto acabado. Assim, por decorrência, o jejum tem por finalidade reduzir a incidência de ruptura intestinal durante a evisceração e propagação de microrganismos nas carcaças (GONÇALVES et al., 2014).

O rendimento de carcaça é menor, quando as aves não são submetidas ao jejum pré-abate ou quando são por um curto período (LYON et al., 1991), este resultado é consequente do alimento consumido tempo antes do abate, ser totalmente eliminado com as vísceras. Outro fator agravante, é a possibilidade de maior contaminação de carcaças, em que as vísceras estarão repletas de ingesta, facilitando o extravasamento ou ruptura.

Por outro lado, quando o período de jejum é exacerbado, pode resultar em perda de peso vivo (GARCIA et al., 2008), prejuízos ao bem-estar animal (WANG et al., 2013), multiplicação de microrganismos como Salmonella sp. no papo (HINTON et al., 2000) e ceco (BURKHOLDER et al., 2008), fragilidade intestinal e consequentemente, contaminação das carcaças durante 0 processamento, bem como perda na qualidade de carne (BRIZIO et al., 2015).

O Ministério da Agricultura, Pecuária e Abastecimento (MAPA) preconiza um tempo mínimo de seis horas e um máximo de oito horas de suspensão da ração para as aves que serão abatidas (BRASIL, 1998). Por sua vez, as legislações brasileiras, de modo geral, preconizam técnicas ou manejos no pré-abate que visam ao bem-estar dos animais, mas não dispõem de uma normalização específica para cada etapa posterior ao jejum. E a recomendação de não ultrapassar 12 horas de jejum total (LUDKE et al., 2010), acaba sendo negligenciada, principalmente, pelos tempos excessivos na espera do abatedouro.

Neste sentido, é crescente a preocupação da sociedade com os métodos de produção e abate dos animais. Estes princípios éticos se sobressaem entre as novas tendências de mercado, em que, os consumidores mais exigentes têm demonstrado interesse em adquirir produtos obtidos, preconizando-se o bemestar dos animais.

A qualidade de carne, também se impõe com uma nova demanda social e de mercado. As variações nos parâmetros de qualidade são geralmente atribuídas às más condições do manejo ante mortem e às modificações metabólicas no processo post mortem, as quais desencadeiam transtornos fisiológicos que podem causar alterações bioquímicas anômalas, afetando, com isso, a aparência, pH, textura e suculência da carne (DADGAR et al., 2012).

Dentre as propensões mais valorizadas pelo mercado alimentício está a "confiabilidade e qualidade", que se referem aos consumidores mais conscientes e informados, que demandam produtos seguros e de qualidade atestada. Aliada à essa preocupação, o MAPA estabeleceu, desde 2006, uma política de zero tolerância para a presença de material gastrointestinal e biliar em carcaças de frangos (BRASIL, 2006). Esse material na superfície de carcaça deve ser removido, com rejeição total da porção contaminada, uma vez que a área afetada pode indicar 
pontos prováveis de contaminação microbiológica, ameaçando a saúde do consumidor (BRIZIO et al., 2015).

Assumindo a importância do bem-estar animal, da segurança do alimento para a sociedade e a manutenção de atributos de qualidade da indústria avícola, objetivou-se com esta revisão bibliográfica, abordar os principais efeitos da prática do jejum pré-abate no metabolismo animal, integridade intestinal e qualidade de carne de frangos de corte.

\section{DESENVOLVIMENTO}

\section{Jejum pré-abate e metabolismo animal}

O jejum pré-abate de frangos de corte inicia na granja, com a interrupção do acesso das aves ao alimento, e a restrição hídrica, se dará somente algumas horas preliminares à apanha. $O$ tempo de jejum total adotado rotineiramente pelas granjas comerciais é de 6 a 12 horas (KOMIYAMA et al., 2008), no entanto, esse tempo pode sofrer variações, sendo dependente de alguns fatores como: a logística de transporte, o período de espera no abatedouro, a capacidade de alojamento e a velocidade de abate da indústria.

NIJDAM et al. (2004) realizaram um estudo na Holanda e constataram que o tempo médio de transporte entre granja e abatedouro era de 2 h e 20 min., mas este tempo poderia ser de até $3 \mathrm{~h}$ e $30 \mathrm{~min}$. Já o tempo de espera observado, em média, foi de 2 h e $30 \mathrm{~min}$, e o tempo máximo de 15 h e 55 min. Portanto, o período de jejum total, que inicia na granja e finaliza na insensibilização, poderia ser de $12 \mathrm{~h}$ e $45 \mathrm{~min}$ a um cenário extremo de $33 \mathrm{~h}$ e $30 \mathrm{~min}$.

No Brasil, uma pesquisa com o mesmo objetivo de retratar as estatísticas do manejo pré-abate de um abatedouro comercial, revelou a média do tempo de transporte de $1 \mathrm{~h}$ e $30 \mathrm{~min}$, sendo o tempo máximo registrado de $4 \mathrm{~h}$, e para o tempo de espera no abatedouro foi constatado uma média de 2 h e 58 min e máximo de 17 h e 38 min (VIEIRA et al., 2011). LUDTKE et al. (2010) visando o bem-estar animal e redução das perdas na qualidade de carne recomendam que o tempo jejum total para aves não ultrapasse 12 horas. Assim, pode-se concluir que na prática de uma indústria avícola, os tempos de jejum total rotineiramente ultrapassam 0 recomendado de 12 horas.

O período de jejum exacerbado, causado principalmente por longos tempos de espera no abatedouro, altera o metabolismo dos frangos de corte, provocando uma mudança de anabolismo ao catabolismo, de lipogênese a lipólise e uma taxa metabólica reduzida (NIJDAM et al., 2005).

Esse manejo praticado de forma errônea tem efeito negativo, não só do ponto de vista econômico, mas também em relação ao bem-estar animal. As consequências do estresse em aves são mudanças no comportamento, nos parâmetros fisiológicos, hematológicos, enzimáticos e hormonais, e ainda, alterações patológicas (VOSMEROVA et al., 2010).

A perda de peso vivo e mortalidade durante o manejo pré-abate estão relacionados à duração do jejum e as condições ambientais durante o transporte e espera no abatedouro. Pode-se observar, variações de 0,5 a $2 \%$ de perda de peso da granja até a entrada do abatedouro e de a 0,5 a $1 \%$, até o momento de abate, enquanto a mortalidade observada rotineiramente na recepção pode ser de até $1 \%$ (MENDES et al., 2011).

Umas das alterações fisiológicas que pode ocorrer na ave se o jejum préabate prolongar é a desidratação que provoca perda no peso vivo, refletindo sobre o 
peso da carcaça quente e fria, além disso, a fome e sede gera desconforto ao animal (GARCIA et al., 2008; VANDERHASSELT et al., 2013).

Ajustes de comportamento podem ocorrer rapidamente e a um custo menor do que os ajustes fisiológicos. PEREIRA et al. (2013) observaram que houve uma piora nas características comportamentais de frangos de corte com o aumento do tempo de jejum. Após 15 horas de jejum foi certificado que todas as aves estavam deitadas, agressivas (bicando outras aves) e piando com maior intensidade, o que demonstra que as mesmas estavam incomodadas.

O estresse é o principal indicador utilizado para avaliar o bem-estar da ave. Durante o manejo pré-abate, a ave é apresentada a diversos fatores estressantes, e seu organismo responde através de uma combinação de respostas bioquímicas, fisiológicas e comportamentais. Essas reações ajudam a ave a eliminar ou reduzir os aspectos adversos do manejo e do ambiente, como tentativa de resgatar o equilíbrio do organismo (LUDKE et al., 2010).

A concentração de corticosterona a níveis plasmáticos pode se elevar devido ao estresse pré-abate (VOSMEROVA et al., 2010; WHANG et al., 2012). WHANG et al. (2012) compararam diferentes tempos de jejum e efeitos sobre os níveis de corticosterona no plasma e glicogênio muscular. Os resultados apontaram que os animais submetidos a $24 \mathrm{~h}$ de jejum apresentaram níveis maiores de corticosterona do que os frangos do grupo sem restrição alimentar e os de $12 \mathrm{~h}$ de jejum. E ainda, que o declínio de glicogênio correspondeu aos aumentos das horas de jejum, indicando que o estresse ocorreu em resposta ao longo tempo de privação de alimento.

Em situações de jejum prolongado e exaustão muscular, a corticosterona estimula a glicogenólise muscular e hepática na tentativa de restabelecer a homeostase do organismo, oferecendo maior aporte energético. ZHANG et al. (2009) e NIJDAM et al. (2005) quando submeteram frangos às etapas pré-abate e aumentaram os tempos restrição alimentar perceberam quadro de hipoglicemia em frangos de corte, resultante da exaustão dos estoques de glicogênio hepático.

Enzimas, como CK e LDH, têm sido propostas como indicadores sensíveis de estresse em animais. O aumento destas enzimas no sangue é considerado indício de lesões musculares esqueléticas e fadiga muscular causado por estresse severo (XING et al. 2015).

Para obtenção de suporte extra de energia, uma sequência de reações é realizada para o catabolismo da glicose, sendo que, o lactato é o produto final da glicólise anaeróbia. A conversão de piruvato a lactato é catalisada pela enzima lactato desidrogenase (LDH). Em resposta ao estresse psicológico sofrido e ao jejum prolongado pode haver aumento desta enzima no plasma, que tem sido utilizada como indicador do estresse dos animais no momento do abate. Eminentes concentrações plasmáticas desta enzima podem identificar animais com danos musculares, e assim consequente problema na qualidade de carne (MARCHI et al., 2012).

O estresse do transporte e manejo pode conduzir a liberação de corticosteroides endógenos, resultando em mudanças no hemograma. 0 leucograma do estresse observado em mamíferos, também pode ser encontrado em aves, com a presença do aumento de leucócitos e heterófilos e decréscimo dos linfócitos (DONELEY, 2011).

Foi proposto por BLACK et al. (2011) que uma maneira de quantificar o grau de estresse seria a alteração da razão heterófilos e linfócitos $(H / L)$ no sangue. Nesta conjuntura de extenuação prolongada, os animais exibem um quadro de 
depressão imunológica, com aumento no valor da proporção $H / L$ e uma redução na contagem total de leucócitos relativa à contagem de eritrócitos.

As concentrações no plasma de glicose, triglicerídeos (TG) e ácido úrico mensurados durante o jejum podem ser uma indicação do balanço energético negativo. Frangos que não tiveram acesso à alimentação antes da apanha apresentaram maior concentração do hormônio tetraiodotironina (T4) e menores níveis de triiodotironina (T3), TG e glicose em comparação com frangos que tiveram acesso a alimentação antes das etapas pré-abate (NIJDAM et al., 2005).

Devido à queda dos níveis de glicose no plasma durante o jejum, e consequentemente de insulina, há início de lipólise no tecido adiposo. Pela ação das lipases, os ácidos graxos são liberados das moléculas de TG, com o aumento dos níveis de ácidos graxos não esterificados (NEFA). NIJDAM et al. (2005) relataram que frangos submetidos ao jejum antes do transporte obtiveram maiores níveis de NEFA no soro quando comparados aos frangos alimentados. Resultado similar ao encontrado por ZHANG et al. (2009), ao qual relataram que a concentração deste metabólito foi significativamente maior para os frangos submetidos ao maior tempo de transporte e de espera no abatedouro contribuindo, assim, para prolongar o tempo do jejum total.

O excesso de carboidratos e proteínas usados na conversão de TG (lipogênese) ou lipídios dietéticos são algumas das fontes das quais os animais utilizam os ácidos graxos como aporte energético. No entanto, ambas as fontes que formam TG estão ausentes ou são apresentadas em pequena extensão quando os frangos são mantidos em jejum pré-abate (NIJDAM et al., 2005).

VOSMEROVA et al. (2010), que monitoraram os níveis de TG em diferentes tempos de transporte granja-abatedouro e concluíram que, as aves que permaneceram maior tempo de jejum, correspondente aos maiores tempos de transporte, obtiveram os menores valores para TG.

\section{Jejum pré-abate e morfologia intestinal}

A preservação da superfície intestinal depende da manutenção das células epiteliais na membrana plasmática apical, bem como as junções de oclusão intercelulares. A ruptura das junções oclusivas ou alteração conformacional das suas proteínas estruturais podem afetar a integridade intestinal (SONG et al., 2014).

Estudos in vivo com animais desafiados por Salmonella Typhimurium demonstraram perda na integridade epitelial no intestino de aves com redução na expressão das proteínas ocludina e claudina (ZHANG et al., 2012; SHAO et al., 2013). Os mesmos resultados foram observados em animais submetidos ao estresse térmico (SONG et al., 2014), entretanto, a repercussão do estresse do jejum pré-abate sobre expressão das proteínas de junções oclusivas no trato gastrointestinal de aves não foi relatada.

O estresse fisiológico, psicológico e ambiental são fatores promotores da quebra da integridade da barreira intestinal e aumento na permeabilidade a macromoléculas em modelos animais (SONG et al., 2014; VICUNA et al., 2015; KUTTAPPAN et al., 2015).

É por meio da barreira intestinal intacta que há proteção contra a invasão de microorganismos e toxinas, por outro lado, esta barreira deve ser aberta para absorver líquidos e solutos essenciais. Tais metas opostas são alcançadas através da permeabilidade intestinal (BISCHOFF et al., 2014). KUTTAPPAN et al. (2015) reportaram que a restrição alimentar de 29 horas alterou a permeabilidade e função de barreira intestinal em frangos de corte. 
A altura e relação vilo/cripta são amplamente utilizados como marcadores de integridade mucosa e função intestinal. THOMPSON \& APPLEGATE (2006) conduziram experimento para verificar o efeito do jejum pré-abate na morfologia intestinal e verificaram que a integridade intestinal e a capacidade do intestino de prevenção à colonização de patógenos se mostraram comprometidas durante longos períodos de jejum alimentar. A restrição alimentar teve efeitos deletérios no epitélio de absorção do intestino, resultando na redução da altura das vilosidades e profundidade das criptas.

Em contraste a estes resultados, PEREIRA et al. (2013) avaliaram o efeito de 6, 9, 12 e 15 horas de restrição alimentar antes do abate, nas características morfológicas da mucosa do duodeno, jejuno e ceco de frangos. Os autores relataram que não houve alterações significativas na morfometria que pudessem comprometer a integridade intestinal.

A exposição de fatores estressantes pode, também, causar mudanças na produção de muco epitelial. Qualquer alteração qualitativa ou quantitativamente na secreção de mucina pode afetar a eficiência de proteção da barreira intestinal (ZHANG et al., 2012). Uma redução linear na quantidade de muco que reveste o trato intestinal ao longo de 24 horas de jejum foi constatada por THOMPSON \& APPLEGATE (2006), no entanto, o número de células caliciformes encontradas nas vilosidades do indivíduo não foi afetado.

Períodos de jejum total acima do recomendado, após 12 horas, debilitam as paredes intestinais. Com 18 horas de jejum, o intestino estará muito frágil e se cortará, ou se romperá, com muita facilidade. Nesse caso, a bílis será liberada contaminando a carcaça (MENDES \& KOMIYAMA, 2011). BRIZIO et al. (2015) também evidenciaram que em períodos de jejum prolongado (mais de 12 horas), os intestinos e vesícula biliar se tornam tênue, aumentando a tendência de ruptura.

A microbiota intestinal é considerada um componente defensivo da barreira. O papel desempenhado pelas comunidades bacterianas é limitar o crescimento excessivo de microorganismos e proteger seus hospedeiros contra a invasão de potenciais agentes patogênicos (HUANG et al. 2015). São reconhecidos fatores ambientais que promovem o desequilíbrio da microbiota intestinal, como o jejum pré-abate que simultaneamente, favorece a multiplicação dos microrganismos patogênicos no papo e intestino. Logo após a alimentação, há uma redução no $\mathrm{pH}$ do papo devido à produção bacteriana de ácido lático. Esta redução do $\mathrm{pH}$ contribui para a digestão via hidrólise do alimento estocado, além de produzir um efeito bacteriostático ou bactericida sobre as bactérias sensíveis à essa faixa de $\mathrm{pH}$. Diminuições significativas na população de bactérias láticas no papo, ocorrem dentro de seis horas após iniciar a retirada de alimentação (HINTON et al., 2000)

Um dos efeitos indesejáveis do jejum pré-abate é a diminuição da capacidade natural do papo em inibir a colonização de Salmonella sp. e outras enterobactérias, como foi verificado por HINTON et al. (2000). Os autores mostraram que houve alta proliferação de enterobactérias e aeróbios cecais com a diminuição concomitante de bactérias láticas no papo de frangos de corte submetidos a $24 \mathrm{~h}$ de jejum.

BARREIRO et al. (2012) explicam que durante o jejum pré-abate, com o esvaziamento do trato gastrintestinal, ocorre aumento do $\mathrm{pH}$ devido à diminuição da população de bactérias ácido-láticas, favorecendo eventualmente a instalação e multiplicação de determinados microrganismos patogênicos.

O estresse ambiental tem mostrado ser um fator que além de induzir a colonização dos patógenos entéricos, facilita a transmissão horizontal de patógenos 
entre animais, e contribui para contaminação de carcaça durante o processamento. A fonte de estresse mais comum no pré-abate é o jejum e a exposição a altas temperaturas, que estão associados com o aumento da susceptibilidade intestinal para colonização de Salmonella Enteritidis (BURKHOLDER et al., 2008).

Esse fato pode ser esclarecido por THOMPSON et al. (2008) que relataram que o jejum pré-abate gera impacto sobre a microbiota, com reduções nas populações e diversidade bacteriana proporcionalmente ao aumento do tempo de restrição alimentar, inviabilizando a exclusão competitiva que tem por objetivo prevenir a instalação e colonização de bactérias indesejáveis na mucosa intestinal.

Os resultados de CORRIER et al. (1999) relatam, também, o aumento da colonização de Salmonella sp. no papo durante o jejum, o que o torna um potencial contaminante na linha de abate. O aumento significativo nas contagens de Salmonella sp. no papo foi associada à tendência de os frangos consumirem cama contaminada nos galpões durante a restrição alimentar.

Nos períodos curtos de jejum alimentar, menores que seis ou sete horas, o trato digestório das aves se mantém cheio de alimento, não sendo suficiente para reduzir a quantidade de ingesta, facilitando o extravasamento e contaminação de carcaça durante a evisceração (BARREIRO et al., 2012). Diminuições significativas nos pesos do papo ocorrem dentro de quatro a seis horas depois de iniciado o jejum, no entanto, no intestino grosso mesmo após 16 horas de restrição alimentar foi possível constatar conteúdo no órgão (HINTON et al., 2000).

Ocorre a contaminação, quando há rompimento das vísceras do trato digestório, ou quando as fezes que ficam aderidas às penas, pele e pernas entram em contato com a carcaça das aves durante o processamento (BARREIRO et al., 2012). Este conteúdo intestinal contamina o exterior do frango durante o transporte, já que as caixas de transporte são empilhadas em caminhões e as aves nos andares inferiores recebem material fecal das aves presentes nos andares superiores.

Considera-se material contaminante no abatedouro o alimento, fezes, bile, material de cama e sujidades aderidas a penas e pele de aves (MENDES \& KOMIYAMA, 2011). Mas, a maior incidência de contaminação é a fecal e a biliar (BRIZIO et al., 2015).

\section{Jejum pré-abate e qualidade de carne}

O processo de conversão do músculo em carne, com diferentes graus de degradação enzimática e desnaturação de proteínas podem resultar em marcantes variações nas propriedades da carne, como a capacidade de retenção de água, cor, maciez, sabor e suculência. Embora existam outros fatores intrínsecos como idade e genética, o estresse pré-abate, causado por longos períodos de jejum, manejo inadequado e exposição a altas temperaturas têm sido relatado como determinante desencadeador de alterações fisiológicas no animal que ameaçam a qualidade da carne em frangos de corte (LUDKE et al., 2010)

Quando um animal morre por asfixia resultante da sangria, o músculo e as células continuam a consumir e produzir ATP, enquanto, as fontes de glicogênio estiverem disponíveis. No entanto, as reservas energéticas se esgotam rapidamente em anaerobiose e, como consequência, há formação de ácido lático. A queda inicial do $\mathrm{pH}$ é devida, principalmente, à liberação de íons $\mathrm{H}_{+}$, que ocorre antes da redução do piruvato a lactato. Normalmente, o sistema circulatório leva o ácido lático produzido de volta ao fígado (resíntese de glicose e glicogênio, ou coração metabolizado em $\mathrm{CO}_{2}$ e água). Como não há mais circulação após abate, o mesmo se acumula no músculo. Esse processo acontece até a depleção do glicogênio 
muscular ou o pH muscular, se torna tão baixo que as enzimas glicolíticas se tornam inativas (Rigor mortis). O ácido láctico provoca diminuição no $\mathrm{pH}$ sarcoplasmático a ponto de inibir a glicólise, e a produção de ATP, eventualmente, cessa (GREASER, 1986).

Os animais que são submetidos ao estresse do jejum, por apresentarem menor conteúdo de glicogênio nos músculos, resultam em carnes com maior valor de $\mathrm{pH}$ em relação a animais com alto teor de glicogênio muscular (FLETCHER, 2002). Ademais, estas condições podem resultar em rigor mortis atípico sendo totalmente estabelecido na primeira hora, mesmo antes da carcaça ser levada à câmara fria, posto que as reservas energéticas não são suficientes para sustentar o metabolismo anaeróbio e produzir ácido lático. Quanto maior o tempo de jejum, maior a depleção de energia. O jejum prolongado diminui as concentrações de glicogênio muscular e de ATP, reduzindo as taxas de glicogenólise (WANG et al., 2013).

$\mathrm{O} \mathrm{pH}$ inicial normalmente diminui de 7,2 até valores finais de 5,8. Um $\mathrm{pH}$ final 24 horas post mortem menor ou maior que este valor é considerado anormal, constituindo um defeito na qualidade da carne. Considerando os critérios para qualidade de carne, a carne pálida, mole e exsudativa, que provém das palavras em inglês Pale, Soft e Exudative (PSE), em frangos de corte é resultante das más condições do manejo ante mortem e das alterações metabólicas no processo post mortem, provocando aceleração da glicólise, como consequência do estresse agudo no pré-abate (FLETCHER, 2002).

Outro defeito que altera as características organolépticas da carne tem condição escura, firme e seca, com sigla inglesa DFD, que significa dark, firm e dry. Essa carne apresenta um pH alto (acima de 6,0) em virtude das insuficientes reservas de glicogênio no momento do abate, causadas pelo estresse prolongado (DADGAR et al., 2012).

Os valores de luminosidade da carne $\left(\mathrm{L}^{*}\right)$ e $\mathrm{pH}$, como foi proposto por BARBUT et al. (2005), são utilizados para categorizar amostras de carne em DFD $\left(\mathrm{pH}>6.1\right.$ e $\left.\mathrm{L}^{*}<46,0\right)$, normal $\left(5,7 \leq \mathrm{pH} \leq 6,1\right.$ e $\left.46,0 \leq \mathrm{L}{ }^{*} \leq 53\right)$ e PSE $\left(\mathrm{pH}<5,7\right.$ e $\mathrm{L}^{*}>$ $53,0)$. Quando $\mathrm{o} \mathrm{pH}$, após 24 horas, do abate permanece alto pela menor quantidade de ácido lático formada, as proteínas miofibrilares se encontram muito acima de seu ponto isoelétrico, o que aumenta o número das suas cargas positivas, e a água se liga rapidamente nessas proteínas. Nessas condições, há alta capacidade de retenção de água das fibras musculares, apresentando aspecto seco na superfície (LUDKE et al., 2010).

A cor desempenha importante papel na qualidade sensorial da carne e destaca-se como principal fator de apreciação no momento da compra. A coloração da carne é determinada pela concentração total de mioglobina (proteína envolvida nos processos de oxigenação do músculo) e pelas proporções relativas desse pigmento no tecido muscular. Os principais pigmentos heme encontrados na carne de aves são mioglobina, hemoglobina e citocromo C (COSTA et al., 2011).

Entretanto, a cor da carne de frango pode ser afetada por diversos outros fatores, que são variáveis independentes, mas que também interagem, como idade, sexo, linhagem, dieta, gordura intramuscular, condições pré-abate, estresse térmico e também em decorrência de problemas na industrialização, como temperatura de escaldagem e condições de armazenamento e congelamento (FLETCHER, 2002).

A dispersão e reflexão de luz é diretamente proporcional à extensão da desnaturação da proteína, conferindo-Ihe aparência pálida em carnes PSE e, contrariamente, não observado nas DFD, que acabam absorvendo mais a luz 
incidente. As alterações na dispersão de luz afetam a $L^{*}$, com efeito mínimo sobre o teor de vermelho $\left(a^{*}\right)$ e o teor de amarelo $\left(b^{*}\right)$ (FLETCHER, 2002).

KOMIYAMA et al. (2008) verificaram que a $L^{*}$ foi significativamente menor nas aves submetidas ao curto tempo de jejum, quando comparada aos maiores tempos (8, 12 e 16 h). A maciez geralmente decorre de alterações na estrutura miofibrilar, determinadas pelo aparecimento rápido do rigor mortis em função do estresse pré-abate. Esta característica usada para avaliação de qualidade da carne pode ser mensurada pelo teste de força de cisalhamento, ou seja, a força necessária para se "cortar" o pedaço de carne que está sendo testado, sendo que, quanto maior a força necessária, menor é a maciez deste pedaço (MENDES \& KOMIYAMA, 2011). KOMIYAMA et al. (2008) relataram em experimento que a força de cisalhamento de filés de frango aumentou em função do período de jejum (após 8h). No entanto, quando a capacidade de retenção de água foi avaliada, resultados opostos foram detectados, com o menor valor obtido com $4 \mathrm{~h}$ de jejum.

GARCIA et al. (2008) observaram que as carcaças das aves que foram submetidas aos maiores tempos de jejum (13 e 17 horas) apresentaram maior taxa de absorção de água após o resfriamento. Este fato, pode estar associado à maior desidratação das carcaças das aves submetidas a jejum prolongado, levando à maior absorção de água pelas carcaças durante o resfriamento. Em contrapartida, a maior taxa de absorção de água pela carcaça não foi compensada por maior perda de água durante o armazenamento (perda de exsudato) ou cozimento.

Estressores ambientais, físicos e ou psicológicos, oferecidos aos animais cronicamente antes do abate, podem levar ao desenvolvimento de carne DFD, pelo esgotamento dos níveis de glicogênio, devido à exaustão física do animal. Assim como foi reportado por DADGAR et al. (2010), que verificaram que a incidência de carne DFD é maior no inverno, quando as temperaturas são menores que $0^{0} \mathrm{C}$. Os autores concluíram que o estresse causado pelo frio, provoca gasto de material energético para sustentar as contrações musculares motivadas pela demanda por energia. Outros fatores, além da baixa temperatura, podem ser atribuídos ao aparecimento de carnes DFD, o aumento do jejum total dos frangos causado pelos maiores tempos de espera no abatedouro provocou um demasiado consumo das reservas de glicogênio, alterando a transformação bioquímica da carne.

A carne DFD pode ser um problema sério para a saúde pública por estar sujeita a maior risco de alteração microbiana. A ausência de glicose na superfície das carnes DFD permite à microflora, ademais o $\mathrm{pH}$ elevado afeta a conservação da carne, favorecendo o crescimento de bactérias patogênicas. Se esse tipo de carne, análoga à DFD, for embalada à vácuo, o crescimento normal de bactérias láticas não acontece, devido à falta de glicogênio, e, por outro lado, o que se observa é o crescimento de bactérias que causam putrefação, o que reduz a vida de prateleira, além de suprimir as características físicas e organolépticas da carne. (GIL et al., 2015).

\section{CONSIDERAÇÕES FINAIS}

O jejum pré-abate vem sendo constantemente estudado com a finalidade de reduzir seus efeitos negativos sobre o animal e nos parâmetros físico-químicos da carne, porém, mesmo com a geração de novas informações e conhecimento, nota-se, que há aspectos ainda a serem elucidados, principalmente no que tange a segurança alimentar. A preocupação atual é a possibilidade de contaminação de carcaça durante o processamento e subsequente ameaça à saúde do consumidor. 
É pressuposto que a redução da integridade intestinal na ave, contribui para translocação de patógenos e facilita o rompimento de vísceras. Para tanto, não ultrapassar o tempo de jejum total recomendado, adotando-o como uma estratégia que impede a disfunção e manutenção da barreira intestinal, possibilitará o controle da colonização de patógenos entéricos, reduzindo a contaminação dos produtos comestíveis.

O agravante para que o tempo de jejum seja aumentado é principalmente, o tempo de espera no abatedouro. As legislações brasileiras não dispõem de uma normalização que regimenta o tempo de espera para essa espécie, dessa forma, os longos tempos a que as aves são submetidas nos abatedouros prolongam o tempo de jejum, propiciando prejuízos ao bem-estar da ave, qualidade e inocuidade da carne. Portanto, a elaboração de normas regulamentadoras do pré-abate de frangos de corte e o conhecimento do efeito do jejum nos componentes da barreira intestinal assumem importância, de modo a assegurar características físico-químicas, sensoriais e microbiológicas padronizadas, segundo a qual, a carne é adequada ao consumo

\section{REFERÊNCIAS}

BARBUT, S.; ZHANG, L.; MARCONE, L. Effects of pale, normal, and dark chicken breast meat on microstructure, extractable proteins, and cooking of marinated fillets.

Poul Sci, v.84, p.797-802, 2005. Disponível em: http://www.ncbi.nlm.nih.gov/pubmed/15913193

BARREIRO, F.R.; BARALDI-ARTONI, S. M.; PINTO, F. R.; BARBOSA, M. M. C.; BARBOSA, J. C.; AMARAL, L. A. Influence of chlorine added to drinking water during the preslaughter feed withdrawal on microbiology and morphology of the broiler gastrointestinal tract. Poult Sci., v. 91, p. 2778-2784, 2012. Disponível em: <http:// http://ps.oxfordjournals.org/content/91/11/2778 >. doi: 10.3382/ps.2012-02455

BLACK, P.A.; MCRUER, D.L.; HORNE, L. Hematologic parameters in raptor species in a rehabilitation setting before release. J Avian Med Surg, v.25, p.192-198, 2011. Disponível em: http://www.ncbi.nlm.nih.gov/pubmed/22216719. doi: 10.1647/2010024.1

BRASIL, Ministério da Agricultura Pecuária e Abastecimento. Circular n668/2006. Diretrizes para preparação de Plano de APPCC (HACCP) para o processo de abate de aves. Diário Oficial da União, Brasília, DF, 2006.

BRASIL. Ministério da Agricultura, Pecuária e Abastecimento. Portaria №210, de 10 de novembro de 1998. Aprova o regulamento técnico da inspeção tecnológica e higiênico-sanitária de carne de aves. Diário Oficial da União, Brasília, DF, 26 nov. de 1998; Seção 1:226.

BISCHOFF, C.S.; BARBARA, G.; BUURMAN, W.; OCKHUIZEN, T.; SCHULZKE, J.; SERINO, M.; TILG, H.; WATSON, A.; WELLS, J.M. Intestinal permeability - a new target for disease prevention and therapy. BMC Gastroenterology,v.14, p.189, 2014. Disponível em: https://www.ncbi.nlm.nih.gov/pubmed/25407511 DOI:10.1186/s12876-014-0189-7. 
BRIZIO, A.P.D.R.; MARIN, G.; SCHITTLER, L.; PRENTICE, C. Visible contamination in broiler carcasses and its relation to the stages of evisceration in poultry slaughter. Int Food Res J, v. 22, p. 59-63, 2015. Disponível em: http://ifrj.upm.edu.my/22\%20(01)\%202015/(9).pdf

BURKHOLDER, K.M.; THOMPSON, K.L.; EINSTEIN, M.E.; APPLEGATE, T.J.; PATTERSON, J.A. Influence of stressors on normal intestinal microbiota, intestinal morphology, and susceptibility to Salmonella Enteritidis colonization in broilers. Poult Sci, v. 87, p.1734-1741, 2008. Disponível em: http://ps.oxfordjournals.org/content/87/9/1734.long doi: 10.3382/ps.2008-00107.

CORRIER, D.E.; BYRD, J.A.; HARGIS, B.M.; HUME, M.E.; BAILEY, R.H.; STANKER, L.H. Presence of Salmonella in the crop and ceca of broiler chickens before and after preslaughter feed withdrawal. Poult Scie, v.78, p.45-49, 1999. Disponível em: http://www.ncbi.nlm.nih.gov/pubmed/10023745

COSTA, R.G.; SANTOS, N.M.; SOUSA, W.H. Qualidade física e sensorial da carne de cordeiros de três genótipos alimentados com rações formuladas com duas relações volumoso:concentrado. Rev Bra Zootec, v.40, p.1781-1787, 2011. Disponível http://www.scielo.br/scielo.php?script=sci_arttext\&pid=\$151635982011000800023\&l $\mathrm{ng}=\mathrm{en \&} \mathrm{nrm}=$ iso $\mathrm{doi} . \mathrm{org} / 10.1590 / \mathrm{S} 1516-35982011000800023$.

DADGAR, S.; LEE, E.S.; CROWE, T.G., CLASSEN, H.L., SHAND, P.J. Characteristics of cold-induced dark, firm, dry broiler chicken breast meat. Br Poult Sci, v.53, p.351-359, 2012. Disponível em: http://dx.doi.org/10.1080/00071668.2012.695335 doi: 10.3382/ps.2009-00248

DADGAR, S.; LEE, E.S.; LEER, T.L.V.; BURLINGUETTE, N.; CLASSEN, H.L.; CROWE, T.G.; SHAND, P.J. Effect of microclimate temperature during transportation of broiler chickens on quality of the pectoralis major muscle. Poult Sci, v.89, p.1033-1041, 2010. Disponível em: http://ps.oxfordjournals.org/content/89/5/1033.long doi: 10.3382/ps.2009-00248

FLETCHER, D, L. Poultry meat quality. World's Poult Sci, v.58, p.131-145, 2002. doi: 10.1079/WPS20020013.

GARCIA, R.G.; CALDARA, F.R.; VARGAS JUNIOR, F.M.; GRACIANO, J.D.; FREITAS, L.W.; SCHWINGEL, A.W.; MARIN, D.; AMADORI, A.H. Jejum alimentar pré-abate no rendimento e qualidade de carcaça de frangos de corte tipo griller. Agrarian, v.1, p.113-121, 2008. Disponível em: http://www.do.ufgd.edu.br/fernandojunior/arquivos/Artigos/agrarian\%20v\%201\%20n \%20\%202\%20113-121\%202008.pdf.

GIL, M.; FAUCITANO, L.; TALBOT, G.; DEVILLERS, N.; SAUCIER, N. Influence of preslaughter feed withdrawal time applied at the abattoir on carcass microbial quality. Meat Scie, v.99, p.143, 2015. Disponível em: https://www.infona.pl/resource/bwmeta1.element.elsevier-09e5b176-f7b0-3dd08bd8-d4d5d4ca5589 doi: 10.1016/j.meatsci.2014.07.016. 
GONCALVES, G.A.M.; DONATO, T.C.; BAPTISTA, A.A.S.; CORREA, I.M.O.; GARCIA, K.C.O.; ANDREATTI FILHO, R.L. Bacteriophage-induced reduction in Salmonella Enteritidis counts in the crop of broiler chickens undergoing preslaughter feed withdrawal. Poult Sci, v.93, p.216-220, 2014. Disponível em: http://ps.oxfordjournals.org/content/93/1/216.full.pdf+html?sid=3b955e9f-c444-4a639fb8-09b40c43e12a. doi: 10.3382/ps.2013-03360

GREASER, M.L. Conversion of muscle to meat. In: Bechtel PJ. Muscle as food. New York, NY: ed. Academic Press;. pp. 37-102, 1986. Disponível em: http://agris.fao.org/agris-search/search.do?recordID=US882886488

HINTON, A.J.R.; BUHR, R.J.; INGRAM, K.D. Physical, chemical, and microbiological changes in the ceca of broiler chickens subjected to incremental feed withdrawal. Poult Sci, v.79, p.483-488, 2000. Disponível em: http://ps.oxfordjournals.org/content/79/4/483.full.pdf+html?sid=314b86eb-001f-4d4c80f8-7fd0c5bc239d doi: 10.1093/ps/79.4.483

HUANG, Q.; WEI, Y.; LV, Y.; WANG, Y.; HU, T. Effect of dietary inulin supplements on growth performance and intestinal immunological parameters of broiler chickens. Livest Scie., v. 180, p. 173-179, 2015. Disponível em: http://www.livestockscience.com/article/S1871-1413(15)00353-4/abstract?cc=y= DOI: http://dx.doi.org/10.1016/j.livsci.2015.07.015

KOMIYAMA, C.M.; MENDES, A.A.; TAKAHASHI, S.E.; MOREIRA, J.; GARCIA, R.G.; SANFELICE, C.; BORBA, H.S.; LEONEL, F.R.; ALMEIDA, I.C.L.; BALOG, A. Chicken meat quality as a function of fasting period and water spray. Bras $\mathbf{J}$ Poult Sci, v.10, p.179-183, 2008. Disponível em: http://dx.doi.org/10.1590/S1516635X2008000300008

KUTTAPPAN, V.A.; BERGHMAN, L.R.; VICUNA, E.A.; LATORRE, J.D.; MENCONI, A.; WOLCHOK, J.D.; WOLFENDEN, A.D.; FAULKNER, O.B.; TELLEZ, G.I.; HARGIS, B.M.; BIELKE, L.R. Poultry enteric inflammation model with dextran sodium sulfate mediated chemical induction and feed restriction in broilers. Poult Sci., v. 94, p. 1220-1226, 2015. Disponível em: https://www.ncbi.nlm.nih.gov/pubmed/25877409 DOI: $10.3382 / p s / p e v 114$

LUDTKE, C.B.; CIOCCA, J.R.P.; DANDIN, T. ; BARBALHO, P.C. ; VILELA, J.A . Abate Humanitário de Aves. WSPA. 2010:120 p.

LYON, C.E.; PAPA, C.M.; WILSON JR, R.L. Effect of feed withdrawal on yields, muscle pH, and texture of broiler breast meat. Poult Sci, v.70, p.1020-1025, 1991. Disponível

http://ps.oxfordjournals.org/content/70/4/1020.full.pdf+html?sid=c4ea72d2-4799-

4f7e-9ae9-1894ec639b99. doi: 10.3382/ps.0701020

MARCHI, D.F.; SANTILLI, J.C.; SOARES, SANTOS, G. R.; OBA, A.; SHIMOKOMAKI, M.; IDA, E. I. Atividades de creatina quinase e lactato desidrogenase na identificação de frangos com estresse e filés PSE (pale, soft, exudative). Semina: Ciênc. Agrár., Londrina, v. 33, suplemento 2, p. 3103-3110, 2012.

Disponível

em: 
http://www.uel.br/revistas/wrevojs248/index.php/semagrarias/article/view/13559 DOI: http://dx.doi.org/10.5433/1679-0359.2012v33n6Supl2p3103

MENDES, A.A.; KOMIYAMA, C.M. Estratégias de manejo de frangos de corte visando qualidade de carcaça e carne. R Bras Zootec, v.40, p.352-357, 2011. Disponível em: http://www.sbz.org.br/revista/artigos/66290.pdf

NIJDAM, E.; ARENS, P.; LAMBOOIJ, E.; DECUYPERE, E.; STEGEMAN, J.A. Factors influencing bruises and mortality of broilers during, catching, transport, and lairage. Poult Sci, v.83, p.1610-1615, 2004. Disponível em: http://ps.oxfordjournals.org/content/83/9/1610.short doi: 10.1093/ps/83.9.1610

NIJDAM, E.; DELEZIE, E.; LAMBOOIJ, E.; NABUURS, M.J.A. ; DECUYPERE, E. ; STEGEMAN, J.A. Comparison of bruises and mortality, stress parameters, and meat quality in manually and mechanically caught broilers. Poult Sci, v.84, p.467-474, 2005.

em: http://ps.oxfordjournals.org/content/84/3/467.full.pdf+html?sid=174c8ab0-5910-4d99bc1b-4251b0c68eb8 doi: 10.1093/ps/84.3.467

PEREIRA, R.E.P.; MARTINS, M.R.F.B.; MENDES, A.A.;PAZ, I.C.L.; KOMIYAMA, C.M.; MILBRADT, E.L.; FERNANDES, B.C.S. Effects of pre-slaughter fasting on broiler welfare, meat quality, and intestinal integrity. Braz J Poult Sci, v.15, p.119122 , 2013.

Disponível

em:

http://www.scielo.br/scielo.php?script=sci_arttext\&pid=S1516-

$635 X 2013000200007 \& \operatorname{lng}=$ en\& $\mathrm{nrm}=\mathrm{iso}>$.

doi.org/10.1590/S1516$635 \times 2013000200007$.

SHAO, Y.; GUO, Y.; WANG, Z. $\beta-1,3 / 1,6-$ Glucan alleviated intestinal mucosal barrier impairment of broiler chickens challenged with Salmonella enterica serovar Typhimurium. Poult Sci, v.92, p.1764-1773, 2013. Disponível em: http://www.ncbi.nlm.nih.gov/pubmed/23776263 doi: 10.3382/ps.2013-03029

SONG, J.; XIAO, K.; KE, Y.L.; JIAO, L.F.; HU, C.H.; DIAO, Q.Y.; SHI, B.; ZOU, Z.T. Effect of a probiotic mixture on intestinal microflora, morphology, and barrier integrity of broilers subjected to heat stress. Poult Sci, v.93, p.581-588, 2014. Disponível em: http://www.ncbi.nlm.nih.gov/pubmed/24604851 doi: 10.3382/ps.2013-03455

THOMPSON, K.; BURKHOLDER, K.; PATTERSON, J.; APPLEGATE, T.J. Microbial ecology shifts in the ileum of broilers during feed withdrawal and dietary manipulations. Poult Scie, v.87, p.1624-1632, 2008. Disponível em: http://www.ncbi.nlm.nih.gov/pubmed/18648058 doi: 10.3382/ps.2007-00324

THOMPSON, K,L.; APPLEGATE, T.J. Feed withdrawal alters small-intestinal morphology and mucus of broilers. Poult Sci, v.85, p.1535-1540, 2006. Disponível em: http://www.ncbi.nlm.nih.gov/pubmed/16977838

VANDERHASSELT, R.F.; BUIJS, R.; SPRENGER, M.; GOETHALS, K.; WILLEMSEN, H.; DUCHATEAU, L.; TUYTTENS, F.A.M. Dehydration indicators for broiler chickens at slaughter. Poult Sci, v.92, p. 612-619, 2013. Disponível em: http://www.ncbi.nlm.nih.gov/pubmed/23436511 doi: 10.3382/ps.2012-02715. 
VICUNA, E.A.; KUTTAPPAN, V.A. GALARZA-SEEBER, R.; LATORRE, J.D.; FAULKNER, O.B.; HARGIS, B.M.; TELLEZ, G., BIELKE L.R. Effect of dexamethasone in feed on intestinal permeability, differential white blood cell counts, and immune organs in broiler chicks. Poult Sci., v.94, p. 2075-2080, 2015. Disponível em: https://www.ncbi.nlm.nih.gov/pubmed/26195804

DOI:10.3382/ps/pev211

VIEIRA, F.M.C.; SILVA, I.J.O.; BARBOSA FILHO, J.A.D.; VIEIRA, A.M.C.; BROOM, D.M. Preslaughter mortality of broilers in relation to lairage and season in a subtropical climate. Poult Sci, v.90, p.2127-2133, 2011. Disponível em: http://ps.oxfordjournals.org/content/90/10/2127.abstract?sid=9f2c2d19-cb7f-40abbffb-98ef448a4237 doi:10.3382/ps.2010-01170

VOSMEROVA, P.; CHLOUPEK, J.; BEDANOVA, I.; CHLOUPEK, P.; KRUZIKOVA, K.; BLAHOVA, J.; VECEREK V. Changes in selected biochemical indices related to transport of broilers to slaughterhouse under different ambient temperatures. Poult Sci, $\quad$ v.89, p.2719-2725, 2010. Disponível em: http://ps.oxfordjournals.org/content/89/12/2719.full?sid=a343975f-e233-4f8c-8ed54860f451c6e4 doi: 10.3382/ps.2010-00709

WANG, S.; LI, C.; XU, X.; ZHOU, G. Effect of fasting on energy metabolism and tenderizing enzymes in chicken breast muscle early post-mortem. Meat Sci, v.93, p.865-872, 2013. Disponível em: http://dx.doi.org/10.1016/j.meatsci.2012.11.053. doi:10.1016/j.meatsci.2012.11.053

XING, T.; XU, X. L.; ZHOU, G. H. et al. The effect of transportation of broilers during summer on the expression of heat shock protein 70, postmortem metabolism and meat quality. J. Anim. Sci., v. 93, p. 62-70, 2015. Disponível em: https://www.ncbi.nlm.nih.gov/pubmed/25403192 DOI:10.2527/jas.2014-7831

ZHANG, B.; SHAO, Y. ; LIU, D.; YIN, P.; GUO, Y.; YUAN, J.; Zinc prevents Salmonella enterica serovar Typhimurium-induced loss of intestinal mucosal barrier function in broiler chickens. Avian Pathol, v.41(4), p.361-367, 2012. Disponível em: http://www.ncbi.nlm.nih.gov/pubmed/22834550 doi: 10.1080/03079457.2012.692155

ZHANG, L.; YUE, H.Y.; ZHANG, H.J.; XU, L.; WU, S.J.; YAN, H.J.; GONG, Y.S.; QI, G.H. Transport stress in broilers: I. Blood metabolism, glycolytic potential, and meat quality. Poult Sci, v.88, p.2033-2041, 2009. Disponível em: http://www.ncbi.nlm.nih.gov/pubmed/19762854 doi: 10.3382/ps.2009-00128 